\title{
||||||||||||||||||||||||||||||||||||||||||||||||||||||||||||||||||.
}

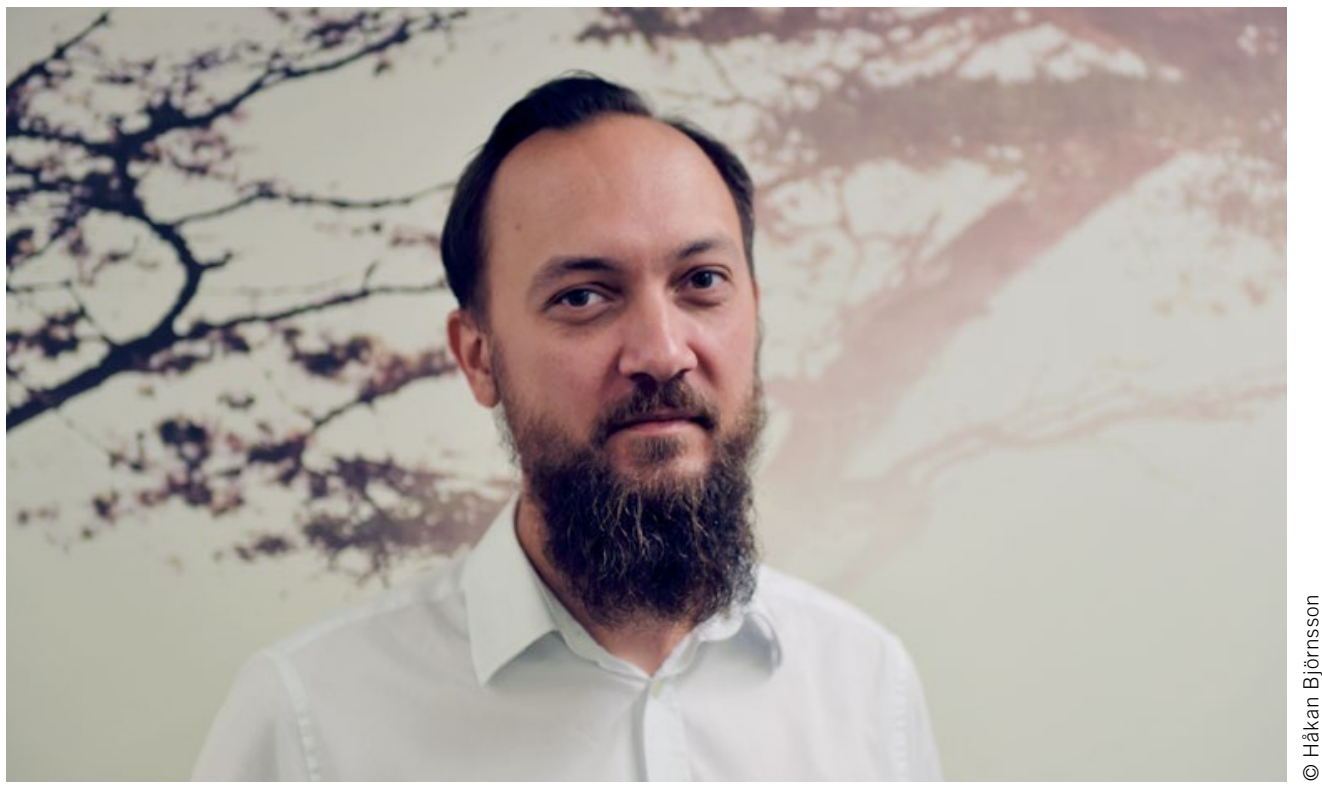

Ragnar Burenius

Leitender Programmingenieur für Verbrennungsmotoren Volvo Göteborg (Schweden)

\section{Neue Anforderungen in einer anderen Normalität}

Ich denke, ich spreche für die meisten von uns, wenn ich sage, dass 2020 bisher tatsächlich ganz anders war. Für diejenigen von uns, die das Glück hatten, eine Ansteckung zu vermeiden, hat sich unser Leben trotzdem durch die notwendigen Einschränkungen zur Begrenzung der Ausbreitung des Corona-Virus verändert. Hoffentlich sind wir auf dem Weg zurück zur Normalität, aber es könnte eine andere Normalität sein als zu Beginn des Jahres. Für uns als Industriezweig waren die Auswirkungen nicht nur der offensichtliche und unvermeidliche Umsatzrückgang, sondern auch eine Umstellung in der Art und Weise, wie wir unsere tägliche Arbeit erledigen. Es ist nicht mehr selbstverständlich, dass man sich mit seinen Kollegen am Wasserspender oder an der Kaffeemaschine zu einem Gespräch trifft, und unsere Interaktionen mit anderen Lieferanten und Kunden erfolgen über die Filter von Skype, Teams und Zoom.

Diese Veränderungen treffen eine Branche, die sich bereits im Umbruch befand. Selbst wenn der Antrieb mit Verbrennungsmotoren in den kommenden Jahren insgesamt die dominierende Antriebsquelle sein wird, wird sich das breitere Angebot an elektrifizierten Produkten auf die Erwartungen der Kunden auswirken. Diejenigen Käufer, für die ein vollelektrisches Auto nicht die passende Wahl ist, werden höchstwahrscheinlich trotzdem schon mit einem Elektroantrieb gefahren sein oder Erfahrungen damit gemacht haben. Damit verbunden sind angepasste Referenzen. Moderne Elektroautos zeichnen sich durch ein hervorragendes Ansprechverhalten und Fahrbarkeit in der Stadt aus.
Warum sollte ich von meinem Luxus-SUV mit Verbrennungsmotor weniger erwarten? Hinzu kommt, dass ein großer Teil des Umsatzwachstums der letzten Jahre in jüngeren Märkten zu verzeichnen war, wo es nicht selbstverständlich ist, dass das leise Brummen eines Autos mit Verbrennungsmotor aus der Vergangenheit Teil von Kindheitserinnerungen ist. Warum sollte mein Auto ein Geräusch machen, wenn es anspringt, und warum vibriert es? Ein breiteres Angebot an Elektroautos könnte bei traditionellen Antrieben einen ebenso starken Einfluss auf die veränderten Kundenerwartungen haben wie auf die Verkaufszahlen.

Ich persönlich glaube, dass der Hybridantriebsstrang in Zukunft eine noch wichtigere Rolle spielen wird. Er ermöglicht es uns, die positiven Eigenschaften des Elektroantriebs, wie schnelles, geräuscharmes Anfahren, anzubieten und gleichzeitig die Stärken des Verbrennungsmotors, nämlich Unabhängigkeit von der Infrastruktur und Vielseitigkeit für Langstreckenfahrten mit hoher Geschwindigkeit, weiter zu verbessern. Die Aufrechterhaltung des Preisniveaus auf dem Massenmarkt wird jedoch hocheffiziente und integrierte Lösungen erfordern. Motoren und Hybridgetriebesysteme müssen gemeinsam entwickelt und für globale Produktionssysteme ausgelegt werden, um Skaleneffekte zu ermöglichen. Dies bedeutet die Notwendigkeit einer engen Zusammenarbeit, sowohl team- und organisationsübergreifend als auch weltweit. Kommunikation und Beziehungen mit Kollegen und Zulieferern werden für uns als Branche wichtiger denn je sein, auch in einer etwas anderen Normalität. 